\title{
Mechanistic Aspects of the Kharasch Addition Reaction Catalyzed by Organonickel(II) Complexes Containing the Monoanionic Terdentate Aryldiamine Ligand System $\left[\mathrm{C}_{6} \mathrm{H}_{2}\left(\mathrm{CH}_{2} \mathrm{NMe}_{2}\right)_{2}-2,6-\mathrm{R}-4\right]^{-\dagger}$
}

\author{
Lucia A. van de Kuil,, $\S$ David M. Grove, ${ }^{\ddagger}$ Robert A. Gossage, ${ }^{\ddagger}$ J an W. Zwikker, \\ Leonardus W. J enneskens, $§$ Wiendelt Drenth, $§$ and Gerard van Koten*, \\ Debye Institute, Departments of Metal-Mediated Synthesis and Physical Organic Chemistry, \\ Utrecht University, Padualaan 8, $3584 \mathrm{CH}$ Utrecht, The Netherlands
}

Received J anuary $28,1997^{\otimes}$

\begin{abstract}
The addition reaction of polyhalogenated alkanes to alkenes (Kharasch addition reaction) is homogeneously catalyzed in the absence of $\mathrm{O}_{2}$ under mild reaction conditions $\left(25^{\circ} \mathrm{C}\right)$ by the arylnickel complexes [ $\left.\mathrm{Ni}^{\prime \prime}\left\{\mathrm{C}_{6} \mathrm{H}_{2}\left(\mathrm{CH}_{2} \mathrm{NMe}_{2}\right)_{2}-2,6-\mathrm{R}-4\right\} \mathrm{Br}\right]\left(\mathrm{R}=\mathrm{H}, \mathrm{MeC}(\mathrm{O}), \mathrm{Cl}, \mathrm{MeO}, \mathrm{NH}_{2}\right)$ and shows a high selectivity for the 1:1 adduct. Kinetic data on the catalytic system with [Ni $\left.\left\{\mathrm{C}_{6} \mathrm{H}_{3}\left(\mathrm{CH}_{2} \mathrm{NMe}_{2}\right)_{2}-2,6\right\} \mathrm{Br}\right](\mathrm{R}=\mathrm{H}$; abbreviated as [Ni(NCN)Br]), methyl methacrylate, and $\mathrm{CCl}_{4}$ reveal a rate of reaction that is first order in nickel complex and in alkene. In our series of para-substituted arylnickel catalysts, the rate of catalysis increases with the el ectron donating character of the para substituents on the aryl ligand and this rate correlates directly with the $\mathrm{Ni} / \mathrm{N} / \mathrm{Ni}^{\prime \prime \prime}$ redox potential. These data, together with separate spectroscopic studies and results from individual experiments employing other solvents, other polyhalogenated alkanes such as $\mathrm{CBr}_{4}$ and $\mathrm{CF}_{3} \mathrm{CCl}_{3}$ and other alkene substrates such as styrene, 1-octene, and cyclohexene, lead to the proposal of a catalytic cycle based on a nonchain mechanism with a mononuclear nickel species. Before or in the rate-determining step oxidation of the $\mathrm{Ni}(\mathrm{II})$ center to $a \mathrm{~d}^{7}$ arylnickel(III) species occurs by a single electron transfer and halide transfer from the polyhalogenated alkane in an inner-sphere activated complex [Ni(NCN)$\left.(\mu-\mathrm{Cl}) \mathrm{CCl}_{4}\right]$. This step generates an organic radical intermediate which is proposed to stay in the coordination sphere of the metal where it reacts with the alkene. The reaction rate decreases with an increase in the steric congestion at the $\mathrm{N}$-donor centers in derivatives of the $\left[\mathrm{Ni}(\mathrm{NCN}) \mathrm{Br}\right.$ ] catalyst (i.e., $\mathrm{NMe}_{2}>\mathrm{NEt}_{2}>\mathrm{NMe}(\mathrm{i}-\mathrm{Pr})>\mathrm{NMe}(\mathrm{t}-\mathrm{Bu})$ ). This behavior is consistent with the characteristics for an inner-sphere electron-transfer process. Selective 1:1 Kharasch product formation then results from a chain transfer in the $\mathrm{Ni}$ (III) coordination sphere by the reverse process, i.e., single el ectron transfer with concomitant halide transfer. Important conclusions of this study are that the initially active site of the catalyst is the $\mathrm{Ni}-\mathrm{X}$ unit (X = halide) and that activation of $\mathrm{CCl}_{4}$ occurs in the absence of a free coordination site.
\end{abstract}

\section{Introduction}

The generation of carbon-carbon bonds is an important reaction step in organic synthesis. One way to form such a bond and, thus, extend a carbon chain is by the addition of a polyhalogenated alkane to an alkene substrate to form a 1:1 adduct, as shown in eq 1 . This<smiles>[R]C([Y16])=CC</smiles>

$\mathrm{X}=$ halogen; $\mathrm{Y}=\mathrm{H}$, halogen, $\mathrm{CF}_{3}$, or other electronegative group

type of reaction is generally known as the Kharasch addition reaction, ${ }^{1}$ and in addition to the formation of a new carbon-carbon $\sigma$-bond, synthetically useful halide

* To whom correspondence should be addressed. E-mail: vankoten@xray.chem.ruu.nl.

tPresented in part at the 6th IUPAC Symposium on Organometallic Chemistry Directed Towards Organic Synthesis, Utrecht, The Netherlands, 1991.

$¥$ Department of Metal-Mediated Synthesis.

$\S$ Department of Physical Organic Chemistry.

${ }^{\otimes}$ Abstract published in Advance ACS Abstracts, October 1, 1997. substituents are introduced at the same time. The application of such 1:1 adducts as synthetic intermediates has been reviewed. ${ }^{2}$ The K harasch addition reaction requires either a free radical precursor as the promotor or a metal complex as the catalyst. The reaction has been extensively investigated both for synthetic purposes and for mechanistic information. The classical free radical chain mechanism is operative not only with initiators such as light, heat, and peroxides, ${ }^{1}$ but also with a variety of metal complexes. ${ }^{3}$ With certain substrates, it can be difficult to select for the

(1) (a) Kharasch, M. S.; Engelmann, H.; Mayo, F. R. J . Org. Chem. 1938, 2, 288. (b) Kharasch, M. S.; J ensen, E. V.; Urry, W. H. Science 1945, 102, 169. (c) Kharasch, M. S.; Elwood, E. V.; Urry, W. H. J . Am. Chem. Soc. 1947, 69, 1100. (d) Kharasch, M. S.; Friedlander, H. N.J . Org. Chem. 1949, 14, 239. (e) Kharasch, M. S.; Sage, M. I bid. 1949, 14, 537. (f) Kharasch, M. S.; Simon, E.; Nudenberg, W. I Ibid. 1953, 18, 328. (g) Walling, C.; Huyser, E. S. Org. React. 1963, 13, 91. (h) Walling, C. Free Radicals in Solution; Wiley: New York, 1963.

(2) Bellus, D. Pure Appl. Chem. 1985, 57, 1827.

(3) (a) Hájek, M.; Silhavy, P.; Málek, J . Collect. Czech. Chem. Commun. 1980, 45, 3488. (b) Maruoka, K.; Sano, H.; Fukutani, Y.; Yamamoto, H. Chem. Lett. 1985, 1689. (c) Grigg, R.; Devlin, J.; Ramasubbu, A.; Scott, R. M.; Stevenson, P. J . Chem. Soc., Perkin Trans. 1 1987, 1515. (d) Friedlina, R. Kh.; Velichko, F. K. Synthesis 1977, 145. 


\section{Scheme 1}

$$
\begin{aligned}
{\left[\mathrm{M}^{\mathrm{n}}\right]+\mathrm{CXCl}_{3} } & \rightleftarrows\left[\mathrm{M}^{\mathrm{n}+1}\right] \mathrm{Cl}+{ }^{\cdot} \mathrm{CXCl}_{2} \\
\mathrm{CH}_{2}=\mathrm{CRR}^{\prime}+{ }^{\cdot} \mathrm{CXCl}_{2} & \longmapsto \mathrm{Cl}_{2} \mathrm{XC}-\mathrm{CH}_{2}-\mathrm{CRR}^{\prime} \\
\mathrm{Cl}_{2} \mathrm{XC}-\mathrm{CH}_{2}-\mathrm{CRR}^{\prime}+\left[\mathrm{M}^{\mathrm{n}+1}\right] \mathrm{Cl} & \rightleftarrows \mathrm{Cl}_{2} \mathrm{XC}-\mathrm{CH}_{2}-\mathrm{CRR}^{\prime} \mathrm{Cl}+\left[\mathrm{M}^{\mathrm{n}}\right]
\end{aligned}
$$

Kharasch addition because of radical stability or activity which leads to chain propagation and, thus, the formation of 1:2 adducts, telomers and/or polymers. The prerequisite for selective 1:1 addition is, thus, controlled chain termination. For metal-complex-catalyzed reactions, the two principal types of mechanisms are primarily discriminated by the role of the metal species.

The first type of mechanism (Scheme 1) invol ves the inclusion of a redox system into the propagation steps of the conventional free radical chain addition. The metal complex then participates both in the initiation and in the chain propagation as a halogen transfer agent, in its oxidized form being a much more reactive halogen donor than the polyhalogenated alkane. ${ }^{4}$ This reaction sequence is commonly encountered in the socalled atom transfer radical addition (ATRA) reactions for $\mathrm{C}-\mathrm{C}$ bond formation in organic synthesis, ${ }^{5,6}$ as well as in controlled living radical polymerization by atom transfer polymerization (ATRAP). ${ }^{7}$ This redox chain mechanism has been postulated for copper and iron halides as catalysts. ${ }^{4 a-i}$

In the second type of Kharasch addition, the mechanism proceeds via a non-chain pathway as depicted in Scheme 2.8 The organic radicals that result from a single electron transfer (SET) between the metal complex and a polyhalogenated alkane are more-or-less 'caged' in the coordination sphere of the metal species. Matsumoto et al. ${ }^{8 a-e}$ and Davis et al. ${ }^{89}$ have proposed

(4) (a) Asscher, M.; Vofsi, D. J . Chem. Soc. 1961, 2261. (b) Asscher, M.; Vofsi, D. I bid. 1963, 1887. (c) Asscher, M.; Vofsi, D. I bid. 1963, 3921. (d) Asscher, M.; Vofsi, D. J . Chem. Soc. B 1968, 947. (e) Orochov, A.; Asscher, M.; Vofsi, D. J . Chem. Soc., Perkin Trans. 2 1973, 1000. (f) Kochi, J . K. Organometallic Mechanisms and Catalysis; Academic Press: New York, 1978. (g) Minisci, F. Acc. Chem. Res. 1975, 8, 165. (h) Hájek, M.; Silhavy, P. Collect. Czech. Chem. Commun. 1983, 48, 1710. (i) Vit, Z.; Hájek, M. I bid. 1987, 52, 1280. (j) Davis, R.; Groves, I. F. J . Chem. Soc., Dalton Trans. 1982, 2281. (k) Tsuji, J .; Sato, K.; Nagashima, H. Chem. Lett. 1981, 1169. (I) Tsuji, J.; Sato, K.; Nagashima, H. Tetrahedron 1985, 26, 393; I bid. 1985, 26, 5003.

(5) Reviews: (a) Curran, D. P. Synthesis 1988, 489. (b) Curran, D. P. I. Free Radicals in Organic Synthesis and Biology; Minisci, F., Ed.; Kluwer: Dordrecht, The Netherlands, 1989; p 37. (c) Curran D. P. In Comprehensive Organic Synthesis; Trost, B. M., Fleming I., Eds.; Pergamon: Oxford, U.K., 1991; Vol. 4, p 715.

(6) (a) Nagashima, H; Ozaki, N.; I shii, M.; Seki, K.; Wakamatsu, H.; I toh, K. J . Org. Chem. 1993, 58, 464. (b) Udding, J . H.; Tuijp, K. J. M.; van Sanden, M. N. A.; Hiemstra, H.; Speckamp, W. N. Ibid. 1994, 59, 1993. (c) Seijas, J. A.; Vazquez-Tato, M. P.; Castedo, L.; Estevez, R. J .; Onega, M. G.; Ruiz, M. Tetrahedron 1992, 48, 1637. (d) Nagashima, H.; Wakamatsu, H.; Ozaki, N.; Ishii, T.; Watanabe, M.; Tajima, T.; I toh, K. J . Org. Chem. 1992, 57, 1682. (e) Hayes, T. K.; Villani, R.; Weinreb, S. M.j. Am. Chem. Soc. 1988, 110, 5533.

(7) (a) Wang, J.-S.; Matyjaszewski, K. J . Am. Chem. Soc. 1995, 117, 5614 and references given therein. (b) Kato, M.; Kamigaito, M. Sawamoto, M.; Higashimura, T. Macromolecules 1995, 28, 1721. (c) Ando, T.; Kato, M.; Kamigaito, M.; Sawamoto, M. I bid. 1996, 29, 1070. (d) Wang, J .-S.; Matyjaszewski, K. I bid. 1995, 28, 7901. (e) Grimaud, T.; Matyjaszewski, K. I bid. 1997, 30, 2216. (f) Percec, V.; Barboiu, B. I bid. 1995, 28, 7970. (g) Haddleton, D. M.; J asieczek, C. B.; Hannon, M. J .; Shooter, A. J . Ibid. 1997, 30, 2190. (h) Granel, C.; Dubois, Ph.; J érôme, R.; Teyssié, Ph. Ibid. 1996, 29, 8576. (i) Mardare, D. Matyjaszewski, K. Macromol. Chem. Phys. 1995, 196, 399. (j) Negaki, H.; Kotani, Y.; Kamigaito, M.; Sawamoto, M. Macromolecules 1997, 30, 2249. (k) Nishikawa, T.; Ando, T.; Kamigaito, M.; Sawamoto, M. Ibid. 1997, 30, 2244. (I) Percec, V.; Barboiu, B.; Neumann, A.; Ronda, J. C.; Zhao, M. I bid. 1996, 29, 3665. (m) Matyjaszewski, K.; Patten, T. E.; Xia, J . J . Am. Chem. Soc. 1997, 119, 674. (n) Patten, T. E.; Xia, J .; Abernathy, T.; Matyjaszewski, K. Science 1996, 272, 866. (o) Webster, O. W. I bid. 1991, 251, 887.

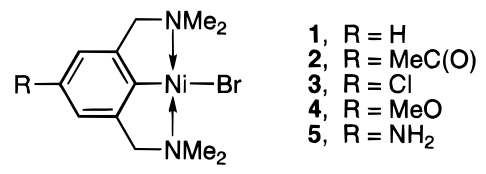

Figure 1. Square-planar arylnickel complexes $\left[\mathrm{Ni}^{\prime \prime}\left\{\mathrm{C}_{6} \mathrm{H}_{2}\left(\mathrm{CH}_{2} \mathrm{NMe}_{2}\right)_{2}-2,6-\mathrm{R}-4\right\} \mathrm{Br}\right], \mathbf{1}-\mathbf{5}$. Complex $\mathbf{1}$ is abbreviated as [Ni(NCN)Br].

\section{Scheme 2}

$$
\begin{aligned}
& \mathrm{CXCl}_{3}+\mathrm{M} \rightleftarrows\left[\mathrm{MCl}-\cdot-\mathrm{CXCl}_{2}\right] \\
& {\left[\mathrm{MCl}-{ }^{-}{ }^{-} \mathrm{CXCl}_{2}\right]+\mathrm{CRR}^{\prime}=\mathrm{CH}_{2} \rightleftarrows\left[\mathrm{MCl} \cdots \cdot\left(\mathrm{CRR}^{\prime}=\mathrm{CH}_{2}\right)^{-\cdots}{ }^{-} \mathrm{CXCl}_{2}\right]}
\end{aligned}
$$

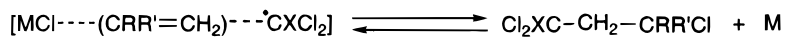

such a mechanism for Kharasch catalysis with complexes of the general formula $\left[\mathrm{MCl}_{2}\left(\mathrm{PPh}_{3}\right)_{x}\right](\mathrm{M}=\mathrm{Ru}, \mathrm{x}$ $=3 ; \mathrm{M}=\mathrm{Ni}, \mathrm{x}=2$ ). Recent studies into applications and mechanisms of the complex-catalyzed Kharasch addition reaction with a variety of metal species ${ }^{9}$ have included a suggestion of another type of mechanism involving oxidative addition of a polyhalogenated alkane to a rhodium(I) complex. ${ }^{9 g}$

Earlier studies in this laboratory ${ }^{10}$ have shown that the arylnickel(II) complex [Ni $\left\{\mathrm{C}_{6} \mathrm{H}_{2}\left(\mathrm{CH}_{2} \mathrm{NMe}_{2}\right)_{2}-2,6-\mathrm{R}\right.$ 4\} $\mathrm{Br}](\mathrm{R}=\mathrm{H} ; \mathbf{1})$, depicted in Figure 1 , is an active homogeneous catalyst for the $K$ harasch addition reaction with a range of polyhalogenated alkanes (eg., $\mathrm{CCl}_{4}$, $\mathrm{CBr}_{4}$, and $\left.\mathrm{CF}_{3} \mathrm{CCl}_{3}\right)$ and a variety of terminal alkenes (eg., methyl methacrylate, styrene, and 1-octene) under mild reaction conditions. ${ }^{10,11}$ Furthermore, we have used the substituent $\mathrm{R}$ to graft the arylnickel moiety not only to polysiloxane polymers ${ }^{12 a}$ and silica ${ }^{12 b}$ but also on to carbosilane dendrimers ${ }^{13}$ and have shown that some of these new (water and organic solvent) soluble materials possess good catalytic activity.12a,13

Recently, as an extension of the metal-catalyzed $K$ harasch addition reaction, Sawamoto et al reported that certain metal complexes can homogeneously polymerize methyl methacrylate (MMA) in the presence of low concentrations of $\mathrm{XCCl}_{3}(\mathrm{X}=\mathrm{Cl}, \mathrm{Br})$ in aromatic media. This process is catalyzed by either $\left[\mathrm{RuCl}_{2-}\right.$ $\left.\left(\mathrm{PPh}_{3}\right)_{3}\right]^{7 \mathrm{~b}, \mathrm{c}}$ or $\left[\mathrm{NiX}_{2}\left(\mathrm{PR}_{3}\right)_{2}\right]^{7 \mathrm{j}}$ in the presence of a Lewis

(8) (a) Matsumoto, H.; Nakano, T.; Nagai, Y. Tetrahedron Lett. 1973, 5147. (b) Matsumoto, H.; Nakano, T.; Nagai, Y. I bid. 1975, 899. (c) Matsumoto, H.; Nakano, T.; Ohkawa, K.; Nagai, Y. Chem. Lett. 1978, 363. (d) Matsumoto, H.; Nakano, T.; Nagai, Y. J . Org. Chem. 1976 41, 396. (e) Matsumoto, H.; Nakano, T.; Takasu, K.; Nagai, Y. I bid. 1978, 43, 1743. (f) Bland, W. J.; Davis, R.; Durrant, J. M. A. J Organomet. Chem. 1985, 280, 95. (g) Bland, W. J .; Davis, R.; Durrant, J. M. A. Ibid. 1985, 280, 397. (h) Hájek, M.; Silhavy, P.; Málek, J. Collect. Czech. Chem. Commun. 1980, 45, 3502. (i) Nondek, L.; Hun, L.-G.; Wichterlová, B.; Krupicka, S. J . Mol. Catal. 1987, 42, 51. (j) Murai, S.; Sugise, R.; Sonoda, N. Angew. Chem. 1981, 93, 481.

(9) (a) Derouet, D.; Brosse, J. C. Eur. Polym. J . 1991, 27, 1125. (b) Kotora, M.; Hájek, M. J. Fluorine Chem. 1991, 55, 57. (c) Hu, C. M.; Qui, Y. L. I bid. 1991, 55, 109. (d) Adamek , F.; Hájek, M.; J anousek Z. Collect. Czech. Chem. Commun. 1992, 57, 1291. (e) Kotora, M.; Hájek, M.; Dobler, R. I bid. 1992, 57, 2622. (f) Kotora, M.; Adamek, F.; Hájek, M. Catal. Lett. 1993, 18, 345. (g) Cable, C.J .; Adams, H.; Bailey, N. A.; Crosby, J .; White, C. J . Chem. Soc., Chem. Commun. 1991, 165.

(10) Grove, D. M.; van Koten, G.; Verschuuren, A. H. M. J . Mol . Catal. 1988, 45, 169.

(11) Grove, D. M.; Verschuuren, A. H. M.; van Koten, G.; van Beek, J. A. M. J . Organomet. Chem. 1989, 372, C1.

(12) (a) van de Kuil, L. A.; Grove, D. M.; Zwikker, J . W.; J enneskens, L. W.; Drenth, W.; van Koten, G. Chem. Mater. 1994, 6, 1675. (b) Pathmamanoharan, C.; Wijkens, P.; Grove, D. M.; Philipse, A. P. Langmuir 1996, 12, 4372.

(13) Knapen, J. W. J .; van der Made, A. W.; de Wilde, J . C.; van Leeuwen, P. W. N. M.; Wijkens, P.; Grove, D. M.; van Koten, G. Nature 1994, 372, 659. 
acid activator, and the experimental data and product composition point to a controlled radical polymerization in both of these systems. An essential difference between this polymerization reaction and the 1:1 Kharasch addition reaction is that polymerization is performed using almost equimolar concentrations of the polyhalogenated alkane and the metal catalyst, whereas a K harasch addition is typically performed under conditions where the metal is used in a $0.01-10 \mathrm{~mol} \%$ quantity relative to the polyhalogenated alkane (and alkene substrate). The controlled radical polymerization concept has been extended by Matyjaszewski and co-workers $\mathrm{c}^{7 \mathrm{~d}, \mathrm{e}}$ for the bulk polymerization of styrene and MMA. This process uses a CuX/2,2'-bipyridine catalyst which is similar to many of the Cu halide/amine systems that are used in Kharasch addition reactions. ${ }^{2-4} \mathrm{~A}$ recent report by Teyssié and collaborators details the similar use of the arylnickel(II) complex (1), first synthesized in this laboratory, ${ }^{14,15 a}$ in a similar manner for a well-controlled radical polymerization of MMA at rather moderate temperatures. ${ }^{7 \mathrm{~h}}$ This report is highly relevant to the interpretation of the new results re ported herein.

The present study of the K harasch addition reaction is primarily aimed at acquiring information about the fundamental steps and mechanism of the catalytic cycle that is operative when $\left[\mathrm{Ni}^{\prime \prime}\left\{\mathrm{C}_{6} \mathrm{H}_{2}\left(\mathrm{CH}_{2} \mathrm{NMe}_{2}\right)_{2}-2,6-\mathrm{R}\right.\right.$ 4\}X] complexes are used as catalysts. These compounds have a number of features that distinguish them from the other metal catalysts previously used to probe the mechanism of this reaction. In particular, monoanionic ligands of the type $\left[\mathrm{C}_{6} \mathrm{H}_{2}\left(\mathrm{CH}_{2} \mathrm{NR}^{\prime} \mathrm{R}^{\prime \prime}\right)_{2}-2,6-\mathrm{R}-4\right]^{-}$usually enforce a terdentate $\mathrm{N}, \mathrm{C}, \mathrm{N}^{\prime}$-coordination geometry at a metal center. ${ }^{14}$ Their $\mathrm{Ni}$ (II) complexes generally have a square planar metal geometry with the direct $\mathrm{M}-\mathrm{C}_{\text {aryl }}$ $\sigma$-bond flanked by two, mutually trans-positioned, orthochelating, tertiary amino substituents. The group $X$ is trans to the aryl unit. ${ }^{15}$ We have al ready reported that the para-substituent $(\mathrm{R})$ influences the $\mathrm{Ni}(\mathrm{II}) / \mathrm{Ni}(\mathrm{III})$ redox potential in such aryldiaminenickel(II) complexes ${ }^{16}$ and we have shown that other modifications of the ligand system can influence (through both steric and electronic factors) both catalysis ${ }^{11,15 c}$ and ligand coordination modes. ${ }^{15 b}$

In this investigation of the Kharasch addition reaction, kinetic experiments have been undertaken using the para-substituted aryldiaminenickel(II) complexes [Ni $\left.\left\{\mathrm{C}_{6} \mathrm{H}_{2}\left(\mathrm{CH}_{2} \mathrm{NMe}_{2}\right)_{2}-2,6-\mathrm{R}-4\right\} \mathrm{Br}\right](\mathrm{R}=\mathrm{H}, \mathrm{MeC}(\mathrm{O}), \mathrm{Cl}$, $\left.\mathrm{MeO}, \mathrm{NH}_{2} ; \mathbf{1}-5\right),{ }^{16}$ depicted in Figure 1 , with MMA as the alkene substrate and $\mathrm{CCl}_{4}$ as the polyhalogenated alkane. An important aspect of this catalytic system is that under the ATRA conditions employed (i.e, a high polyhalogenated alkane/Ni catalyst ratio), there is exclusive formation of the 1:1 Kharasch addition prod-

(14) (a) van Koten, G. PureAppl. Chem. 1989, 61, 1681. (b) Rietveld, M. H. P.; Grove, D. M.; van Koten, G. New J . Chem. 1997, $21,751$.

(15) (a) Grove, D. M.; van Koten, G.; Ubbels, H. J . C.; Zoet, R.; Spek, A. L. Organometallics 1984, 3, 1003. (b) van Beek, J. A. M.; van Koten, G.; Ramp, M. J .; Coenjaarts, N. C.; Grove, D. M.; Goublitz, K.; Zoutberg, M. C.; Stam, C. H.; Smeets, W. J . J .; Spek, A. L. Inorg. Chem. 1991, 30, 3059. (c) van de Kuil, L. A.; Veldhuizen, Y. S. J .; Grove, D. M.; Zwikker, J . W.; J enneskens, L. W.; Drenth, W.; Smeets, W. J J .; Spek, A. L.; van Koten, G. Recl. Trav. Chim. Pays-Bas 1994, 113, 267. (d) Schimmel pfennig, U.; Zimmering, R.; Schleinitz, K. D.; Stösser, R.; Wenschuh, E.; Baumeister, U.; Hartung, H. Z. Anorg. Allg. Chem. 1993, 619, 1931.

(16) van de Kuil, L. A.; Luitjes, H.; Grove, D. M.; Zwikker, J . W.; van der Linden, J . G. M.; Roel ofsen, A. M.; J enneskens, L. W.; Drenth, W.; van Koten, G. Organometallics 1994, 13, 468. ucts, i.e telomerization or polymeric products are not formed. ${ }^{7 h}$ Supplementary spectroscopic and mechanistic experiments with other polyhalogenated alkanes (e.g., $\mathrm{CBr}_{4}$ and $\mathrm{CF}_{3} \mathrm{CCl}_{3}$ ) and other alkene substrates (e.g., cyclohexene and 1-octene) have been used to provide further information regarding the elementary steps of the catalytic process and the nature of possible intermediates. The results show that catalysis is based on a mononucl ear nickel species and that the oxidation potential of $\mathrm{Ni}(\mathrm{II}) / \mathrm{Ni}(\mathrm{III})$ plays an important role. The catalytic cycle we propose involves as a characteristic feature the activation of the polyhalogenated alkane directly at a $\mathrm{Ni}-\mathrm{X}$ bond rather than in a vacant coordination site.

\section{Results}

The Catalytic System 1/MMA/CCl 4 and Its Products. The combination of $\left[\mathrm{Ni}^{11}\left\{\mathrm{C}_{6} \mathrm{H}_{3}\left(\mathrm{CH}_{2} \mathrm{NMe}_{2}\right)_{2}-2,6\right\}\right.$ $\mathrm{Br}$ ], 1, abbreviated as [ $\mathrm{Ni}(\mathrm{NCN}) \mathrm{Br}$ ], as the catalyst with MMA as the alkene substrate, $\mathrm{CCl}_{4}$ as the polyhalogenated alkane, and $\mathrm{CH}_{2} \mathrm{Cl}_{2}$ as the inert solvent at $25^{\circ} \mathrm{C}$ is a highly reactive catalytic system for the Kharasch addition reaction. Total turnover numbers of 1700 are possible with this combination of reagents, and initial turnover frequencies of around $400 \mathrm{~h}^{-1}$ are observed. ${ }^{10,11}$ All the materials of this catalytic system are easily handled, and the 1:1 addition product, 2,4,4,4-tetrachloro-2-methylbutanoic acid methyl ester, can be readily analyzed by GLC. It should be stressed, however, that this catalytic system is $\mathrm{O}_{2}$ sensitive, and thus, all kinetic and mechanistic studies have been carried out under an inert $\left(\mathrm{N}_{2}\right)$ atmosphere.

The ${ }^{1} \mathrm{H}$ NMR spectra and $\mathrm{GC}$ analysis of the volatiles from the reaction of MMA with $\mathrm{CCl}_{4}$ using [Ni(NCN)$\mathrm{Br}$ ] as the catalyst under various conditions show the predominant product to invariably be the 1:1 adduct with a reaction selectivity of more than $99 \%$. In none of the experiments was there any evidence found for the formation of telomeric or polymeric materials (cf., ref 7h). Since free radical polymerization of MMA, which is easily initialized by transition metal complexes ${ }^{17}$ and light, ${ }^{18}$ is known to be fast, ${ }^{17-20}$ the absence of such products al ready directly points to catalysis occurring by a non-free-radical type of mechanism in which the

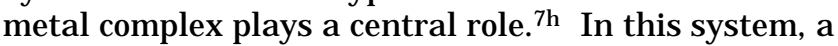
small amount of 2-bromo-4,4,4-trichloro-2-methylbutanoic acid methyl ester (less than $0.3 \%$ ) is formed as a byproduct in the first 5-10 $\mathrm{min}$. Since the bromine atom can only originate from the $[\mathrm{Ni}(\mathrm{NCN}) \mathrm{Br}]$ catalyst, this means that the halide atom of the catalyst is intimately involved in the catalytic process.

Kinetics and Thermodynamic Parameters of the

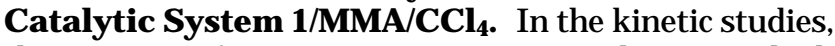
three series of experiments were carried out in which the reaction rate was measured with varying concentrations of the reactants, namely: (i) the arylnickel(II) complex 1, (ii) the alkene MMA, and (iii) the polyhalogenated al kane $\mathrm{CCl}_{4}$ (see Supporting Information).

(17) (a) Bamford, C. H.; Hargreaves, K. Trans. Faraday Soc. 1967 63, 392. (b) Bamford, C. H.; Eastmond, G. C.; Hargreaves, K. Ibid. 1968, 64, 175.

(18) Matheson, M. S.; Auer, E. E.; Bevilacqua, E. B.; Hart, E. J . J Am. Chem. Soc. 1949, 71, 497.

(19) Cowie, J. M. G. Polymers: Chemistry \& Physics of Modern Materials, 2nd ed.; Blackie: Glasgow and London, 1991; Chapter 3.

(20) Davis, T. P.; O'Driscoll, K. F.; Piton, M. C.; Winnik, M. A Macromolecules 1989, 22, 2785. 


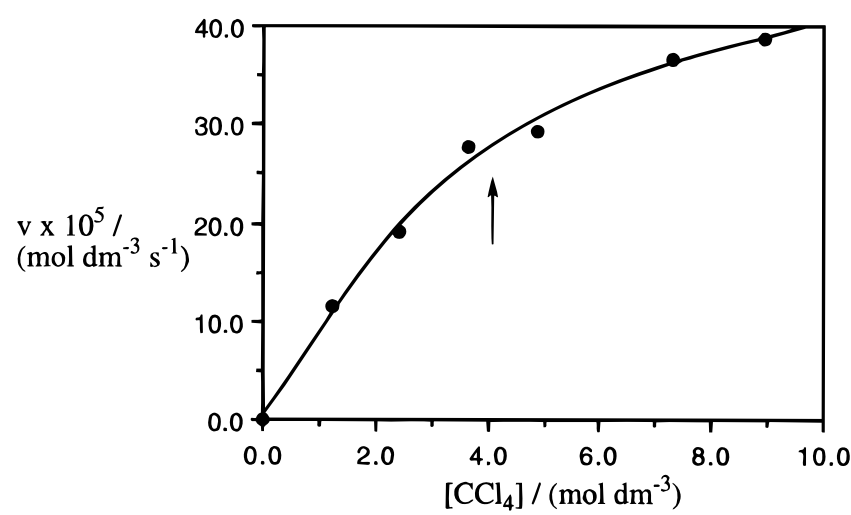

Figure 2. Variation of the initial reaction rate with $\mathrm{CCl}_{4}$ concentration; MMA (3 mL), [Ni(NCN)Br] (30 mg, $9.1 \times$ $10^{-5} \mathrm{~mol}$ ) in $\mathrm{CH}_{2} \mathrm{Cl}_{2}$ (total volume of $25.5 \mathrm{~mL}$ ). The arrow indicates the $\left[\mathrm{CCl}_{4}\right]$ under the standard catalytic conditions (see Experimental Section).

In the first series of experiments, the concentration of nickel complex $\mathbf{1}$ was varied. A linear plot of the rate constants determined vs the concentration of $\mathbf{1}$ indicates a first-order dependence in the arylnickel(II) complex catalyst. Secondly, the rate of conversion of MMA as a function of time was determined under conditions where an excess of $\mathrm{CCl}_{4}$ was present. The plot of the natural logarithm of the concentration of MMA vs time showed distinctly linear behavior indicating a first-order dependence in MMA. Finally, in the third series of experiments, the concentration of $\mathrm{CCl}_{4}$ was varied and the initial rate of reaction determined. When these rates are plotted against $\mathrm{CCl}_{4}$ concentration (Figure 2 ), one obtains a nonlinear relationship. This behavior resembles that encountered with Michaelis-Menten kinetics for enzymes.21 However, this type of rate dependence can al so be explained by saturation kinetics involving prior formation of an adduct radical of the type $\left\{\left[\mathrm{Ni}^{\prime \prime \prime}(\mathrm{NCN}) \mathrm{X}_{2}\right]\left(\mathrm{Cl}_{3} \mathrm{C}^{\circ}\right)\right\}(\mathrm{X}=\mathrm{Cl}, \mathrm{Br})$. In this scheme, there is increased competition between the termination (chain-transfer) reaction of the $\mathrm{Cl}_{3} \mathrm{C} \cdot$ radical (by concomitant electron and halide transfer) and the 1:1 adduct radical with MMA, the latter being the overall forward reaction (product forming step). The inference here is that there is a reversiblestep in the catalytic cycle that involves the $[\mathrm{Ni}(\mathrm{NCN}) \mathrm{X}]$ catalyst and $\mathrm{CCl}_{4}$. Recall that under conditions of low $\mathrm{CCl}_{4}$ concentration, living radical polymerization of $\mathrm{MMA}$ is the dominant reaction. ${ }^{7 \mathrm{~h}}$ For both polymerization and 1:1 Kharasch addition, the polyhalogenated alkane is activated by the catalyst and will, therefore, only appear in the reaction (product) profile if it is present in sufficient quantity. We believe that this activation phenomenon is due to reversible coordination of the $\mathrm{CCl}_{4}$ unit to the $\mathrm{Ni}$ catalyst (above), a concept which will be discussed in more detail below.

Preliminary results ${ }^{11}$ indicated that the polarity of the reaction medium exerts a pronounced effect on the reaction rate of the $[\mathrm{Ni}(\mathrm{NCN}) \mathrm{Br}$-catalyzed Kharasch addition reaction. In the present study, the effects of several solvents, varying from diethyl ether to methanol, on the reaction rate were investigated more quantitatively, and these results are listed in Table 1 . These

(21) (a) For a general discussion, see: Stryer, L. Biochemistry; Freeman: San Francisco, 1981; pp 103-184. (b) I saacs, N. S. Physical Organic Chemistry; Longman: 1987; pp 624-641.
Table 1. Temperature and Solvent Effects on the Rate Constants for Reaction of MMA with $\mathrm{CCl}_{4}$ Catalyzed by $1^{a}$

\begin{tabular}{lccc}
\hline \multicolumn{1}{c}{ solvent } & $\mathrm{T}(\mathrm{K})$ & $\mathrm{E}_{\mathrm{T}} \mathrm{b}$ & $\mathrm{k} \times 10^{5}\left(\mathrm{~s}^{-1}\right)^{\mathrm{c}}$ \\
\hline dichloromethane & 283.3 & 41.1 & 7.3 \\
& 293.4 & 41.1 & 17.4 \\
& 298.5 & 41.1 & 30.7 \\
& 303.7 & 41.1 & 42.4 \\
diethyl ether & 313.2 & 41.1 & 86.0 \\
tetrahydrofuran & 298.2 & 34.6 & 15.9 \\
pyridine & 298.2 & 37.4 & 25.0 \\
acetonitrile & 298.2 & 40.2 & 55.1 \\
methanol & 298.2 & 46.0 & 136.1 \\
& 298.2 & 55.5 & 42.6
\end{tabular}

a Reaction conditions: MMA (3 mL), $\mathrm{CCl}_{4}(10 \mathrm{~mL}),[\mathrm{Ni}(\mathrm{NCN}) \mathrm{Br}$, 1, (30 mg, $\left.9.1 \times 10^{-5} \mathrm{~mol}\right)$, and solvent $(12.5 \mathrm{~mL}) .{ }^{\mathrm{b}} \mathrm{E}_{\mathrm{T}}$ values as a measure for solvent polarity taken from ref $18 .{ }^{c} \mathrm{~K}=\mathrm{k}_{\mathrm{T}} \times\left[\mathrm{CCl}_{4}\right]$ $\times[\mathrm{Ni}(\mathrm{NCN}) \mathrm{Br}]$; Eyring equation: $\ln \left(\mathrm{k}_{\mathrm{T}} / \mathrm{T}\right)=\ln \left(\mathrm{k}_{\mathrm{B}} / \mathrm{h}\right)+\Delta \mathrm{S}^{\ddagger} / \mathrm{R}-$ $\Delta \mathrm{H}^{\ddagger} / \mathrm{RT}$ with $\mathrm{k}_{\mathrm{B}}=$ Boltzmann's constant and $\mathrm{h}=$ Planck's constant.

results clearly show that none of these very different solvents block the catalytic cycle, and in general, increasing the polarity of the reaction medium has a positive effect on the reaction rate. The correlation found by plotting the polarity of the solvent $\left(E_{T}\right.$ values from Reichardt ${ }^{22}$ ) vs the reaction rate is, however, only moderate. When the polarity of the medium is changed in a controlled way by adding various amounts of $\mathrm{CH}_{3}$ $\mathrm{CN}$ to the standard catalytic system, where $\mathrm{CH}_{2} \mathrm{Cl}_{2}$ is the solvent, then a plot of the rate constant against the reaction medium composition shows a linear dependence, i.e., ligating effects of $\mathrm{CH}_{3} \mathrm{CN}$ (and by inference other solvents) are not playing any significant role in the catalytic cycle

Spectroscopic Studies of 1 with Alkenes and Polyhalogenated Alkanes. To understand the cataIytic cycle of the Kharasch addition reaction, it is necessary to have information on the separate interactions of the catalyst $\mathbf{1}$ with the alkene substrate and the polyhal ogenated alkane.

A likely interaction of the metal complex with an olefin is $\eta^{2}$-alkene coordination. To investigate this possibility, solutions of $\mathbf{1}$ with added terminal alkenes (e.g., MMA, styrene, and 1-octene) were studied under various conditions using IR and NMR spectroscopies. The data showed no evidence for $\eta^{2}$-coordination of the alkene functionality to the metal complex in solution. However, with MMA, the IR data do point to $\eta^{1-O}$ coordination between the alkene's carbonyl function and the metal complex. When an excess of $\mathbf{1}$ is added to an MMA solution, the $\mathrm{C}=\mathrm{O}$ stretch absorption band of MMA at $1720 \mathrm{~cm}^{-1}$ shifts to $1580 \mathrm{~cm}^{-1}$. This lowering of the $\mathrm{C}=\mathrm{O}$ band frequency arising from coordination of a carbonyl functionality to a metal center is well recognized.23a We have also recently found when using other arylnickel (II) complexes as catalysts in the Kharasch addition reaction that the presence of ester functionalities on the nitrogen donor substituents can block catalysis and lead to the formation of stable ionic arylnickel (III) complexes having intramolecular $\eta^{1}-\mathrm{O}-$ coordination. ${ }^{24}$

(22) (a) Reichardt, C.; Harbusch-Görnert, E. Liebigs Ann. Chem. 1980, 721. (b) Reichardt, C. Solvents and Solvent Effects in Organic Chemistry; VCH Verlagsgesellschaft GmbH: Weinheim, 1988; pp 285338. (c) Reichardt, C. Chem. Rev. 1994, 94, 2319.

(23) (a) Hesse, M. Spectroscopic Methods in Organic Chemistry; George Thieme Verlag: Stuttgart, 1987. (b) Connor, J .; Riley, P. I. J Chem. Soc., Dalton Trans. 1979, 1318. 
The possibility of a particular interaction of the metal complex catalyst with the polyhalogenated alkane can be inferred from the fact that the bromine atom of [Ni(NCN)Br], 1, does become incorporated into the 1:1 Kharasch addition product. An earlier observation that the ionic species $\left[\mathrm{Ni}\left\{\mathrm{C}_{6} \mathrm{H}_{3}\left(\mathrm{CH}_{2} \mathrm{NMe}_{2}\right)_{2}-2,6\right\}\left(\mathrm{CH}_{3} \mathrm{CN}\right)\right] \mathrm{BF}_{4}$ does not catalyze the Kharasch addition reaction had already emphasized the importance of a metal-halide functionality in the catalyst (vide infra). ${ }^{\text {hh,10,11 }}$ Significantly, analysis by GLC and GC-MS of a mixture of $\mathbf{1}$ alone with $\mathrm{CCl}_{4}(1: 1)$ in $\mathrm{CH}_{2} \mathrm{Cl}_{2}$ revealed that $\mathrm{CBrCl}_{3}$ had been formed, and this confirms that interaction of the $\mathrm{Ni}-\mathrm{Br}$ bond of $\mathbf{1}$ and $\mathrm{CCl}_{4}$ is an important fundamental feature. This conclusion is in line with the kinetic results obtained on the catalytic system where saturation of the catalyti cally active site by excess $\mathrm{CCl}_{4}$ occurs. These GLC and GC-MS analyses also showed the absence of hexachloroethane (that can arise from the combination of two $\mathrm{Cl}_{3} \mathrm{C} \cdot$ radicals), and this is extra evidence that the interaction and further reaction between the nickel complex and carbon tetrachloride does not follow a free radical pathway. This implies that efficient reversible transfer of the $\mathrm{Cl}_{3} \mathrm{C} \cdot$ radical occurs by single electron/halide transfer at a [ $\left.\mathrm{Ni}^{\prime \prime \prime}(\mathrm{NCN}) \mathrm{X}_{2}\right]$ site to regenerate the $\left[\mathrm{Ni}{ }^{\prime \prime}(\mathrm{NCN}) \mathrm{X}\right]$ catalyst and $\mathrm{Cl}_{3} \mathrm{CX}$.

Since $\mathrm{Ni}(\mathrm{II})$ complexes $[\mathrm{Ni}(\mathrm{NCN}) \mathrm{X}]$ are readily oxidized by $\mathrm{X}_{2}$ or $\mathrm{CuX}$ to the corresponding stable $\mathrm{Ni}$ (III) complexes [Ni(NCN) $\left.\mathrm{X}_{2}\right](\mathrm{X}=\mathrm{Cl}, \mathrm{Br}$ or I $),{ }^{25}$ there was a distinct possibility that the interaction of $\mathbf{1}$ with $\mathrm{CCl}_{4}$ might afford paramagnetic $\mathrm{Ni}$ (III) complexes that could be detected by ESR spectroscopy. First, the ESR spectrum of a mixture of $\mathbf{1}$ and $\mathrm{CCl}_{4}$ in $\mathrm{CH}_{2} \mathrm{Cl}_{2}$ was measured at low temperature (see Figure 3a). Second, an active catalytic reaction mixture consisting of MMA, $\mathrm{CCl}_{4}$, and $\mathrm{I}$ in $\mathrm{CH}_{2} \mathrm{Cl}_{2}$ was investigated. After catalysis had been running for a few minutes, a sample of the solution was taken and transferred to an ESR tube (under $\mathrm{N}_{2}$ atmosphere), which was immediately cooled with liquid nitrogen. This mixture gave, at $77 \mathrm{~K}$, the spectrum depicted in Figure 3b. For comparative purposes, the ESR spectrum of an authentic sample of $\left[\mathrm{Ni}{ }^{I I I}(\mathrm{NCN}) \mathrm{Cl}_{2}\right]$ is shown in Figure 3c. The ESR spectra of square-pyramidal complexes [ $\left.\mathrm{Ni}^{\prime \prime \prime}(\mathrm{NCN}) \mathrm{X}_{2}\right]$ can be interpreted in terms of a low-spin $\mathrm{d}^{7} \mathrm{Ni}$ (III) system with the unpaired electron in $\mathrm{a} \mathrm{d}_{\mathrm{z}^{2}}$ orbital which is involved in bonding with an apical halide atom. ${ }^{25}$ The remarkable similarity between the spectra of Figures $3 a, b$ and that of 3c proves that $\mathrm{Ni}$ (III) species are present in the mixtures containing $\mathbf{1}$ and $\mathrm{CCl}_{4}$. In the spectrum of Figure $3 a$, the $g_{z}$ tensor pattern can be seen to arise from two overlapping signals with different hyperfine couplings, viz. 27 and $141 \mathrm{G}$. These values for the hyperfine coupling are in agreement with those found for [ $\mathrm{Ni}^{\prime \prime \prime}$. $(\mathrm{NCN}) \mathrm{Cl}_{2}$ ] $(28 \mathrm{G})$ and [Ni"l $(\mathrm{NCN}) \mathrm{Br}_{2}$ ] (140 G). ${ }^{25 \mathrm{~b}} \mathrm{We}$ conclude, therefore, that a mixture of $\mathbf{1}$ and $\mathrm{CCl}_{4}$ alone is able to produce $\mathrm{Ni}$ (III) species containing chloro and bromo ligands. Note that the ESR hyperfine coupling only reflects the nature of the apical halide and that ESR tensor values are not sufficiently sensitive to the basal halide to allow discrimination of the dihal o species

(24) van de Kuil, L. A.; Veldhuizen, Y. S. J .; Grove, D. M.; Zwikker, J. W.; J enneskens, L. W.; Drenth, W.; Smeets, W. J.J .; Spek, A. L.; van Koten, G. J . Organomet. Chem. 1995, 488, 191.

(25) (a) Grove, D. M.; van Koten, G.; Zoet, R.; Murrall, N. W.; Welch, A. J . J . Am. Chem. Soc. 1983, 105, 1379. (b) Grove, D. M.; van Koten, G.; Mul, P.; Zoet, R.; van der Linden, J . G. M.; Legters, J .; Schmitz, J . E. J .; Murall, N. W.; Welch, A. J . Inorg. Chem. 1988, 27, 2466.



Figure 3. X-band ESR spectra of (a) $\left[\mathrm{Ni}^{\prime \prime}\left\{\mathrm{C}_{6} \mathrm{H}_{3}\left(\mathrm{CH}_{2^{-}}\right.\right.\right.$ $\left.\left.\mathrm{NMe}_{2}\right)_{2}-2,6\right\} \mathrm{Br}$ ] mixed with $\mathrm{CCl}_{4}$ in $\mathrm{CH}_{2} \mathrm{Cl}_{2}$. Arrows indicate the $\mathrm{g}_{\mathrm{z}}$ tensor with hyperfine coupling due to bromide. (b) $\left[\mathrm{Ni}^{\prime \prime}\left\{\mathrm{C}_{6} \mathrm{H}_{3}\left(\mathrm{CH}_{2} \mathrm{NMe}_{2}\right)_{2}-2,6\right\} \mathrm{Br}\right]$ mixed with $\mathrm{CCl}_{4}$ and $\mathrm{MMA}$ in $\mathrm{CH}_{2} \mathrm{Cl}_{2}$. The spectra $\mathrm{a}$ and $\mathrm{b}$ were measured at $77 \mathrm{~K}$ with $\mathrm{g}=2.0036$ indicated with a dashed line. (c) [Ni $\left.{ }^{\prime \prime \prime}\left\{\mathrm{C}_{6} \mathrm{H}_{3}\left(\mathrm{CH}_{2} \mathrm{NMe}_{2}\right)_{2}-2,6\right\} \mathrm{Cl}_{2}\right]$ in toluene glass at $150 \mathrm{~K}$ with $\mathrm{g}=2.002$ indicated by the dashed line.

$\left[\mathrm{Ni}(\mathrm{NCN}) \mathrm{X}_{\text {apical }} \mathrm{X}_{\text {basal }}\right]$ from mixed species [Ni(NCN)$\mathrm{X}_{\text {apical }} \mathrm{Y}_{\text {basal }}$ ] ( $\mathrm{X}$ and $\mathrm{Y}$ can be $\mathrm{Cl}$ or $\mathrm{Br}$ ) which may also be present. Furthermore, when a $\mathrm{Ni}(\mathrm{III})$ complex [Ni$(\mathrm{NCN}) \mathrm{X}_{2}$ ] is formed, one would also expect the concomitant formation of a $\mathrm{Cl}_{3} \mathrm{C} \cdot$ radical, but we have been unable to find any evidence for the latter. ${ }^{23 \mathrm{~b}}$ As a final point, it must be stressed that the intensities of the $\mathrm{Ni}$ (III) ESR signals obtained from the catalytic mixture have not been quantified, and at this stage we cannot definitively say whether these signals are directly associated with intermediates in the predominating catalytic cycle.

Catalysis Using 1 with Other Alkenes and Polyhalogenated Alkanes. The comparative reactivity of several alkene substrates determined using $\mathrm{CCl}_{4}$ as the polyhal ogenated al kane and $\mathbf{1}$ as the catalyst are listed in Table 2. The catalyzed addition reactions of these alkenes, like that of MMA, are regiospecific and antiMarkovnikov with, in general, high selectivity for formation of the 1:1 adduct.

The reactivity can be interpreted in terms of steric hindrance and resonance stability of the radical intermediates. For example, 1,2-disubstituted alkenes have a low reactivity that is probably determined by steric hindrance. Resonance stability seems to play a role in affording a higher reactivity for MMA than for methyl 
Table 2. Comparison of the Reactivity of Several Alkenes ${ }^{a}$

\begin{tabular}{|c|c|c|c|c|}
\hline substrate & $\begin{array}{c}\text { [Cat]/[Alkene] } \\
\text { (\%) }\end{array}$ & $\begin{array}{c}\text { conversion }{ }^{\mathrm{b}} \\
\text { (\%) }\end{array}$ & $\begin{array}{c}\mathrm{k} \times 10^{5} \\
\left(\mathrm{~s}^{-1}\right)\end{array}$ & $\begin{array}{c}\text { selectivity } \\
\text { for } 1: 1 \text { adduct }\end{array}$ \\
\hline methyl methacrylate & 0.32 & $65^{c}$ & 29.8 & 100 \\
\hline styrene & 0.35 & $56^{c}$ & 22.2 & 100 \\
\hline methyl acrylate & 0.33 & $23^{c}$ & 6.6 & 100 \\
\hline 1-octene & 0.32 & $13^{c}$ & 3.9 & 100 \\
\hline cyclohexene & 0.31 & $12^{\mathrm{d}}$ & 0.04 & $86^{e}$ \\
\hline methyl crotonate & 0.32 & $2^{d}$ & $f$ & 100 \\
\hline dimethyl maleate & 0.33 & $0^{d}$ & & \\
\hline dimethyl fumarate & 0.33 & $0^{d}$ & & \\
\hline
\end{tabular}

a Reaction conditions: $\mathrm{CCl}_{4}(10 \mathrm{~mL}),\left[\mathrm{Ni}(\mathrm{NCN}) \mathrm{Br}\right.$ ] $\left(30 \mathrm{mg}, 9.1 \times 10^{-5} \mathrm{~mol}\right)$, and $\mathrm{CH}_{2} \mathrm{Cl}_{2}(12.5 \mathrm{~mL})$ at $25^{\circ} \mathrm{C}$. ${ }^{\mathrm{b}}$ Conversion determined by GLC and selectivity by GLC and GC-MS. ' Conversion determined after $1 \mathrm{~h}$. ${ }^{\mathrm{d}}$ Conversion determined after $24 \mathrm{~h}$. e The $1: 1$ adduct is formed in a cis/trans ratio of 1:2; side products formed: $12 \%$-chlorocyclohexene and $12 \% \mathrm{CHCl}_{3} .{ }^{\mathrm{f}}$ Value not determined.

Table 3. Competition Experiments: Methyl Methacrylate (MMA) versus 1-Octene ${ }^{a}$

\begin{tabular}{cccc}
\hline & \multirow{2}{*}{$\begin{array}{c}\text { substrate ratio } \\
\text { exp no. }\end{array}$} & \multicolumn{2}{c}{$\mathrm{k} \times 10^{5}\left(\mathrm{~s}^{-1}\right)$} \\
\cline { 3 - 4 } & MMA:1-octene & $\mathrm{MMA}$ & 1-octene \\
\hline 1 & $1: 0$ & $33.5 \pm 1.2$ & \\
3 & $0: 1$ & & $3.9 \pm 0.5$ \\
4 & $9: 1$ & $33.9 \pm 2.8$ & $2.8 \pm 0.2$ \\
5 & $1: 9$ & $41.3 \pm 2.4$ & $4.1 \pm 0.2$ \\
& $1: 1$ & $38.4 \pm 0.7$ & $3.2 \pm 0.2$
\end{tabular}

a Reaction conditions: $\mathrm{CCl}_{4}(10 \mathrm{~mL}),[\mathrm{Ni}(\mathrm{NCN}) \mathrm{Br}](30 \mathrm{mg}, 9.1$ $\left.\times 10^{-5} \mathrm{~mol}\right)$, and $\mathrm{CH}_{2} \mathrm{Cl}_{2}(12.5 \mathrm{~mL})$ at $25{ }^{\circ} \mathrm{C}$. bTotal alkene concentration is constant $(1.1 \mathrm{~mol} / \mathrm{L})$.

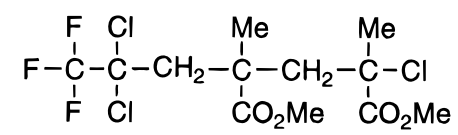

Figure 4. The $1: 2$ adduct obtained from the reaction of $\mathrm{CCl}_{3} \mathrm{CF}_{3}$ with MMA.

acrylate. Only with the internal alkene cyclohexene (that affords primarily the cis and trans 1:1 adducts in a 1:2 ratio) is there a significant formation of byproducts, namely 3-chlorocycl ohexene and chlor oform (in an approximate 1:1 ratio). Chloroform could arise from allylic hydrogen abstraction by a $\mathrm{Cl}_{3} \mathrm{C} \cdot$ radical, and a subsequent reaction between the resulting cycl ohexenyl radical and $\mathrm{CCl}_{4}$ could generate 3-chlorocyclohexene (and a $\mathrm{Cl}_{3} \mathrm{C} \cdot$ radical). ${ }^{\text {th }}$ The significance of this result is discussed later.

To gain further insight into the role of the alkene in this catalytic system, competition experiments were performed using a 1:1 mixture of a more reactive alkene, MMA, and a less reactive alkene, 1-octene. No products other than the expected 1:1 adducts of these two alkenes were observed with GLC. The observed rate constants of this mixed system are given in Table 3; compared to the pure al kenes, one sees that there is a slight increase of the rate constant for MMA and a corresponding slight decrease of that for 1-octene.

Several polyhalogenated compounds have also been tested in the Kharasch addition reaction with $\mathbf{1}$ as the catalyst and MMA as the alkene substrate. The following order of decreasing reactivity was found: $\mathrm{CBrCl}_{3}$ $>\mathrm{CBr}_{4}>\mathrm{CCl}_{4}>\mathrm{CCl}_{3} \mathrm{CF}_{3}$, and all of these compounds except $\mathrm{CCl}_{3} \mathrm{CF}_{3}$ show an excellent selectivity for formation of a 1:1 adduct; with $\mathrm{CBrCl}_{3}$, the product is 2-bromo-4,4,4-trichloro-2-methylbutanoic acid methyl ester. In the case of $\mathrm{CCl}_{3} \mathrm{CF}_{3}$, the slowest reacting polyhalogenated compound, one obtains together with the major $1: 1$ adduct about $10 \%$ of the $1: 2$ adduct which was identified by GC-MS (see Figure 4). With $\mathrm{CCl}_{3} \mathrm{CF}_{3}$, there is also formation of a small amount of $1,1,1,4,4,4-$ hexafluoro-2,2,3,3-tetrachlorobutane that can arise from dimerization of two $\mathrm{CF}_{3} \mathrm{CCl}_{2}{ }^{\circ}$ radicals. Thus, there is evidence of a later reaction of the 1:1 product radical with an additional alkene monomer which competes with subsequent chain transfer of the 1:1 product radical by SET and halogen transfer at a $\left[\mathrm{Ni}(\mathrm{NCN}) \mathrm{X}_{2}\right]$ site.

The exchange of the bromine atom of $[\mathrm{Ni}(\mathrm{NCN}) \mathrm{Br}$, $\mathbf{1}$, with chlorine atoms of carbon tetrachloride (vide supra) prompted us to study cross-over experiments between $\mathrm{CBr}_{4}$ and $\mathrm{CCl}_{4}$ in the absence and presence of MMA. In the first series of experiments, $\mathrm{CCl}_{4}$ and $\mathrm{CBr}_{4}$ were mixed and addition of $\mathbf{1}$ afforded three new compounds which were identified by GC-MS as $\mathrm{CBrCl}_{3}$, $\mathrm{CBr}_{2} \mathrm{Cl}_{2}$ and $\mathrm{CBr}_{3} \mathrm{Cl}$. No dimeric products such as hexachloroethane or hexabromoethane, which could arise from the recombination of $\mathrm{Cl}_{3} \mathrm{C} \cdot$ or $\mathrm{Br}_{3} \mathrm{C} \cdot$ radicals, were detected. No exchange of halide was observed in control experiments in which $\mathbf{1}$ was not present in a solution of $\mathrm{CCl}_{4}$ and $\mathrm{CBr}_{4}$. Thus, the arylnickel complex is essential for the observed halogen exchange. In the second series of cross-over experiments, MMA was treated with a mixture of $\mathrm{CCl}_{4}$ and $\mathrm{CBr}_{4}$ in the presence of $\mathbf{1}$. In this reaction mixture, $\mathrm{CBr}_{4}$ is consumed much faster than $\mathrm{CCl}_{4}$. Analysis of the reaction mixture with GLC and GC-MS showed that eight new compounds, all 1:1 adducts, had been formed (see Figure 5). The formation of these different products can be easily explained on the basis of the cross products from $\mathrm{CCl}_{4}$ and $\mathrm{CBr}_{4}$ that are present in the reaction mixture. Moreover, in separate experiments, we found that halogen exchange between the 1:1 adducts and excess $\mathrm{CCl}_{4}$ can occur under the influence of $\mathbf{1}$. This shows that under the standard conditions of the Kharasch addition reaction, the 1:1 adduct can be considered as a dormant species for which activation of its $\mathrm{C}-\mathrm{X}$ bond is less likely than that for $\mathrm{CCl}_{4}$.

Modification of the Aryldiamine Ligand System. An important aspect of the catalyst system based on aryldiamine metal complexes, such as $\mathbf{1 - 5}$, is that the ligands offer, through modification and substitution, the ability to influence the reactivity of the complexed metal center (see Figure 1). Possible modifications include (i) changing the anion $X_{1}^{10,11,15 a, 25}$ (ii) substituting the methyl groups on the $\mathrm{N}$-donor atoms for other organic groups (e.g., Et, i-Pr, t-Bu), ${ }^{11,15 b}$ and (iii) placing substituents on the aryl ring of the ligand system para to the metal center. ${ }^{16}$ The first two modifications have already been investigated in our laboratory, and both have a marked effect on the catalytic activity of the resulting arylnickel(II) complexes. ${ }^{11}$ The essential role of the anion $\mathrm{X}$ in the present catalytic system having 
<smiles>COC(=O)C(C)(Cl)CC(Cl)(Cl)Cl</smiles><smiles>COC(=O)C([14CH3])(Br)CCBr</smiles><smiles>COC(=O)C(Br)(Br)CC(F)(F)Cl</smiles><smiles>COC(=O)C(Cl)(Cl)CC(C)(Br)Br</smiles><smiles>COC(=O)C(C)(Cl)CCC(Br)(Br)Br</smiles><smiles>COC(=O)C(C)(Br)CCC(Br)(Br)Br</smiles><smiles>COC(=O)C(Cl)(Cl)CCC(Br)(Br)Br</smiles><smiles>COC(=O)C([N])(Br)CCC(Br)(Br)Br</smiles>

Figure 5. Products ( $1: 1$ Kharasch addition) from the cross-over experiment with $M M A$ in the presence of $\mathrm{CCl}_{4}$ and $\mathrm{CBr}_{4}$. Reaction conditions: $\mathrm{MMA}(3 \mathrm{~mL}),[\mathrm{Ni}(\mathrm{NCN}) \mathrm{Br}]\left(30 \mathrm{mg}, 9.1 \times 10^{-5} \mathrm{~mol}\right), \mathrm{CBr}_{4}(16.8 \mathrm{~g}, 51 \mathrm{mmol}), \mathrm{CCl}_{4}(5 \mathrm{~mL}, 52 \mathrm{mmol})$, $\mathrm{CH}_{2} \mathrm{Cl}_{2}(12.5 \mathrm{~mL})$.

been dramatically illustrated by the fact that when $\mathrm{X}$ is a halide $(\mathrm{Cl}, \mathrm{Br}$ or $\mathrm{I})$ the metal complexes do display catalytic activity. However, the ionic species [Ni$\left.\left\{\mathrm{C}_{6} \mathrm{H}_{3}\left(\mathrm{CH}_{2} \mathrm{NMe}_{2}\right)_{2}-2,6\right\}\left(\mathrm{CH}_{3} \mathrm{CN}\right)\right] \mathrm{BF}_{4}$ does not exhibit any catalytic activity whatsoever. The latter result is noteworthy and provides indirect evidence that within the catalytic system being studied, $\mathrm{Ni}-\mathrm{X}$ dissociation to form a cationic nickel species does not appear to afford a catalytically active species, even though an "open" coordination site is available. The bulk of the substituents on the $\mathrm{N}$-donor atoms also have a pronounced effect on the reactivity of the nickel(II) complexes $\left[\mathrm{Ni}\left\{\mathrm{C}_{6} \mathrm{H}_{3}\left(\mathrm{CH}_{2} \mathrm{NR}^{\prime} \mathrm{R}^{\prime \prime}\right)_{2}-2,6\right\} \mathrm{Br}\right]$. Contrary to what could be expected from electron donor properties, the activity decreases considerably in the following order: $\mathrm{Me}>\mathrm{Et}>\mathrm{i}-\mathrm{Pr}>\mathrm{t}-\mathrm{Bu}$, i.e., it decreases with increasing steric bulk at the $\mathrm{N}$-donor atom. ${ }^{11}$ This observation corroborates with the view that the initial process is comprised of the formation of an inner-sphere activated complex between $[\mathrm{Ni}(\mathrm{NCN}) \mathrm{X}]$ and the polyhalogenated alkane (eq 2). Increased steric congestion at the $\mathrm{N}$ -

$$
\left[\mathrm{Ni}^{\prime \prime}(\mathrm{NCN}) \mathrm{X}\right]+\mathrm{CCl}_{4} \underset{\mathrm{k}_{-1}}{\stackrel{\mathrm{k}_{1}}{\rightleftarrows}} \underset{\text { inner-sphere complex } \mathbf{A}}{\left[\mathrm{Ni}(\mathrm{NCN}) \times\left(\mathrm{ClCCl}_{3}\right)\right]}
$$

$$
\mathbf{A} \rightleftarrows\left[\mathrm{Ni}{ }^{\prime \prime}(\mathrm{NCN}) \mathrm{Cl}\right]+\mathrm{CCl}_{3} \mathrm{X}
$$

donor atoms will increasingly interfere with the formation of an inner-sphere complex. The same argument applies to the encounter of the 1:1 polyhalogenated alkane addition product $\mathrm{Cl}_{3} \mathrm{CCH}_{2} \mathrm{C}(\mathrm{Cl}) \mathrm{HMeCOOMe}$, instead of $\mathrm{CCl}_{4}$, with a $\mathrm{Ni}(\mathrm{II})$ center. Note al so that the sensitivity of the cone angle to the steric bulk of the substituents is much more pronounced for tertiary amines ( $\mathrm{N}$-donors) than for tertiary phosphines ( $\mathrm{P}$ donors) since the covalent radius of nitrogen is smaller than that of phosphorus. ${ }^{15 b}$ The third modification involving the introduction of substituents $(R)$ with either electron-donating or el ectron-withdrawing character at the para-position of the aryl ring, which should thereby directly influence the el ectronic properties of the $\mathrm{C}_{\text {ipso }}-$ $\mathrm{Ni}$ bond and the metal center, is also investigated in this mechanistic study.

The arylnickel(II) complexes $\left[\mathrm{Ni}\left\{\mathrm{C}_{6} \mathrm{H}_{2}\left(\mathrm{CH}_{2} \mathrm{NMe}_{2}\right)_{2-}\right.\right.$ 2,6-R-4\}Br] (R = H (1), $\mathrm{MeC}(\mathrm{O})$ (2), $\mathrm{Cl}$ (3), $\mathrm{MeO}$ (4), $\mathrm{NH}_{2}$ (5)), see Figure 1 , were synthesized ${ }^{16}$ and their catalytic ability in the addition reaction was tested. The results of these experiments show that compared to $\mathbf{l}(R=H)$, electron-withdrawing groups retard the reaction rate while electron-donating groups enhance the reaction rate. The effects of the para-substituents on the cataIytic activity (as the relative reaction rate constant) correlate well with the Hammett substituent constants $\sigma_{\mathrm{p}}$. The negative slope $(\rho=-1.6)$ indicates that there is an electron demand just before or in the ratedetermining step. Previously, we showed that substituents in the para-position of the aryl ring influence the electronic properties of the arylnickel (II) complexes, and redox properties of the various compl exes were quantified by cyclic voltammetry in dichloromethane or acetone solutions. ${ }^{16} \mathrm{~A}$ plot of the oxidation potential of 1-5 from these earlier studies vs the corresponding catalytic reaction rate constant determined here shows a reasonable correlation (see Supporting I nformation). Since the oxidation of $\mathbf{1 - 5}$ is a one-electron transfer process (to afford a $\mathrm{Ni}(\mathrm{III})$ center), this correlation we have now identified indicates that just before or in the ratedeterming step of the catalytic cycle a oneelectron oxidation probably occurs.

\section{Discussion}

All evidence in this study of the Kharasch addition reaction points to a central role for the aryldiamine nickel halide complex in the catalytic cycle. An earlier piece of evidence that corroborates this conclusion is the fact that the steric bulk of the nitrogen donor substituents, which can influence the approach of substrates and reagents to the metal center, does indeed affect the catalytic rate. ${ }^{11}$

Careful consideration of all the collected data of the present and earlier studies ${ }^{10,11,15 a-c, 16,25}$ allows one to propose a catalytic cycle that is not only consistent with the experimental evidence but which also provides insight into the relationship between Kharasch addition and living radical polymerization reactions that are catalyzed by the $\mathrm{Ni}$ (II) complexes $\mathbf{1}-\mathbf{5}$. In the following section, we present our proposal for the $[\mathrm{Ni}(\mathrm{NCN}) \mathrm{X}]$ catalyzed Kharasch addition reaction. A key feature of this is a reversible activation/deactivation of the polyhalogenated alkane by concomitant SET and halide transfer in the $[\mathrm{Ni}(\mathrm{NCN}) \mathrm{X}]$ coordination sphere. This proposal has also been used to explain the controlled radical polymerization of MMA by these complexes. ${ }^{7 \mathrm{~h}}$

Proposed Catalytic Cycle. The proposed catalytic cycle is outlined in Figure 6 with a terminal alkene $\mathrm{H}_{2} \mathrm{C}=\mathrm{CRR}^{\prime}$ as the substrate, carbon tetrachloride as the polyhalogenated alkane, and an arylnickel(II) complex $[\mathrm{Ni}(\mathrm{NCN}) \mathrm{X}]$ as the catalyst. The proposed mechanism consists of three steps. The first step involves the catalyst and $\mathrm{CCl}_{4}$; note that the $\mathrm{CCl}_{4}: \mathrm{Ni}$ ratio is greater than 1000:1, whereas in controlled radical polymerization the polyhalogenated alkane:Ni ratio is lower than $5: 1 .^{7 h}$ In this step, the reversible activation/deactivation of $\mathrm{CCl}_{4}$ occurs. The $\mathrm{Ni}-\mathrm{X}$ moiety of the catalyst is the 




Figure 6. The postulated catalytic cycle for the Kharasch addition reaction of polyhal ogenated alkanes $\left(\mathrm{CCl}_{4}\right)$ to alkenes in the presence of $[\mathrm{Ni}(\mathrm{NCN}) \mathrm{X}], \mathbf{1}$.

anchoring site for the formation of an inner-sphere activated complex (A). It is in this complex that possible $\mathrm{SET} /$ halogen transfer can occur, together with the generation of the $\mathrm{Cl}_{3} \mathrm{C} \cdot$ radical, i.e., formation of a $1: 1$ $\mathrm{Ni}(\mathrm{III}): \mathrm{Cl}_{3} \mathrm{C} \cdot$ radical adduct (see below). In the second step, the alkene is introduced. The third stage is equivalent to the initiation steps and again involves reversible SET/halogen transfer, followed by product elimination and re-generation of the $\left[\mathrm{Ni}^{\prime \prime}(\mathrm{NCN}) \mathrm{X}\right] \mathrm{com}$ plex.

The second step is the rate-determining one, in agreement with the observed first-order dependence in MMA. Consequently, the first step is a rapid equilibrium in which the catalyst $[\mathrm{Ni}(\mathrm{NCN}) \mathrm{X}]$ is likely to be predominately in the form of the inner-sphere complex due to a very large excess of the polyhal ogenated alkane. The first-order in catalyst and the saturation-kinetic behavior of $\mathrm{CCl}_{4}$ are in line with this conclusion.

As a product of the first step, we consider formation of the species $\mathbf{B}$ and $\mathbf{C}$ from the inner-sphere activated complex. Species B is an octahedral Ni(IV) intermediate that arises from a formal oxidative addition of the polyhal ogenated alkane to the $\mathrm{Ni}(\mathrm{II})$ center. The other species, $\mathbf{C}$, is a $\mathrm{Ni}(\mathrm{III})$ intermediate, $\left[\mathrm{Ni}^{\prime \prime \prime}(\mathrm{NCN})(\mathrm{X}) \mathrm{Cl}\right]$ with an associated $\mathrm{Cl}_{3} \mathrm{C} \cdot$ radical, i.e., a complexed radical adduct, which is generated by SET to the activated alkane, followed by halide transfer. Within the coordination sphere of $\mathbf{C}$, there are several ways of stabilizing a $\mathrm{Cl}_{3} \mathrm{C} \cdot$ radical, such as by interactions with the nucleophilic ligand sites of the halide anion or the $\pi$-system of the aryl ring. Species $\mathbf{B}$ and $\mathbf{C}$ are directly interrelated in that homolytic bond cleavage of the $\mathrm{Ni}^{\mathrm{IV}}-\mathrm{CCl}_{3}$ unit in $\mathbf{B}$ would provide a $\mathrm{d}^{7}$ complex with a $\mathrm{Cl}_{3} \mathrm{C} \cdot$ radical, i.e., $\mathbf{C}$.

Our kinetic results allow no discrimination between B and $\mathbf{C}$. We believe, however, that the latter is the more appropriate species for describing and understanding the ensuing (Kharasch and living radical polymerization) chemistry at the metal center. One reason for such a preference is that our experimental data suggests that radical species are involved, although these species are not free radicals. Another reason is based on our electrochemical data, i.e, oxidation of complexes such as $\mathrm{Ni}(\mathrm{II})$ complexes $\mathbf{1}-\mathbf{5}$ to their $\mathrm{Ni}(\mathrm{III})$ analogues is easy but further oxidation to $\mathrm{Ni}$ (IV) has not been achieved. $16,25 \mathrm{~b}$ Supporting evidence is afforded by the results obtained with both electron-donating and electronwithdrawing para-substituents on the aryl ring of the ligand system. We find a reasonable correlation between $E_{\text {ox }}(\mathrm{Ni}(\mathrm{II}) / \mathrm{Ni}(\mathrm{III}))$ of the substituted nickel complexes and their corresponding reactivity. ${ }^{6}$ When the aryl ligand system has pyrrolidine substituents with ester functionalities, catalytic activity is lost since at this oxidation stage additional intramolecular donative $\mathrm{O} \rightarrow \mathrm{Ni}$ coordination stabilizes the $\mathrm{Ni}$ (III) state, i.e., the required termination step by SET/halogen transfer to the product radical is quenched. We have previously isolated and characterized the resulting unique ionic octahedral $\mathrm{Ni}$ (III) complexes. ${ }^{24}$

In the second step, a $\mathrm{C}-\mathrm{C}$ bond is formed in an innersphere reaction of $\mathrm{Cl}_{3} \mathrm{C} \cdot$ with the alkene. This type of association mechanism, in which steric bulk in the metal coordination sphere will influence the catalytic rate, is fully consistent with earlier experimental results with bulkier aryldiamine ligands. ${ }^{15 c}$ The rate-determining step leads to intermediate $\mathbf{D}$, a species about which we have no experimental information (as is the case for $\mathbf{B} / \mathbf{C}$ ). It is clear that in the final stage of the catalytic cycle there has to be rapid SET and transfer of halide between the $d^{7} \mathrm{Ni}(\mathrm{III})$ halide moiety and the adduct radical. The organic product is eliminated from the coordination sphere with regeneration of the [Ni$(\mathrm{NCN}) \mathrm{X}$ ] catalyst. Although in practice in the first cycle it is [ $\mathrm{Ni}(\mathrm{NCN}) \mathrm{Br}$ ] that is the active complex, it will be evident that as soon as the $\mathrm{Br}$ atom has become incorporated into the 1:1 Kharasch addition product that $[\mathrm{Ni}(\mathrm{NCN}) \mathrm{Cl}]$ becomes the catalyst for all remaining cycles.

It is worthwhile to note that step 3 is formally similar to the reverse of step 1 and that the radical in $\mathbf{D}$ is comparable to the $\mathrm{Cl}_{3} \mathrm{C} \cdot$ radical in $\mathbf{C}$. In principle, the radical in $\mathbf{D}$ could add to a second alkene molecule. As shown above in our $\mathrm{CCl}_{4} / \mathrm{MMA}$ system, the kinetics are such that the 1:1 adduct is formed exclusively, but with $\mathrm{CCl}_{3} \mathrm{CF}_{3}$ some $1: 2$ adduct (Figure 4) is isolated. This indicates that slower kinetics for 1:1 adduct formation 
are playing a role with this substrate. Moreover, the 1:1 product $\mathrm{Cl}_{3} \mathrm{CCH}_{2} \mathrm{C}(\mathrm{Cl}) \mathrm{RR}^{\prime}$ is a polyhalogenated alkane like $\mathrm{CCl}_{4}$ and therefore, a potential substrate for activation by [Ni(NCN)X]. Such a subsequent reaction would lead to a 2:1 adduct, but this organic product has not been detected.

Consequences of the Postulated Catalytic Cycle. Any catalytic cycle in which intermediates have radical character brings with it the question of whether free organic radical processes are also operative, particularly in a case such as this where the radicals involved are themselves quite stable (the $\mathrm{CCl}_{3}$ radical is, for example, ca. $42 \mathrm{~kJ} \mathrm{~mol}^{-1}$ more stable than the $\mathrm{CH}_{3}$ radical). As already stated, the first-order dependence of the cataIytic rate on $[\mathrm{Ni}(\mathrm{NCN}) \mathrm{X}]$ concentration is evidence that this is not so, as is our observed reactivity sequence of $\mathrm{CBrCl}_{3}>\mathrm{CBr}_{4}>\mathrm{CCl}_{4}$ which does not agree with the literature sequence ${ }^{\mathrm{h}}$ for a free radical type of mechanism, viz. $\mathrm{CBr}_{4}>\mathrm{CBrCl}_{3}>\mathrm{CCl}_{4}$. The radicals that are involved react much faster within their complex (SET/ halogen transfer) than outside, except for those in the slower reactions with cyclohexene and $\mathrm{CCl}_{3} \mathrm{CF}_{3}$. The rate constant of adduct formation with cyclohexene $(\mathrm{k}$ $=0.04 \times 10^{-5} \mathrm{~s}^{-1}$ ) is three orders of magnitude lower than with MMA. Thus, one does see products arising from a free radical process, i.e., allyl proton abstraction from cyclohexene by $\mathrm{Cl}_{3} \mathrm{C} \bullet$, that is consistent with some release of this radical to the bulk solution.

There are a number of aspects worth briefly commenting on with respect to the relationship of our catalytic system to other results in this general area. The fact that the $\left[\mathrm{Ni}{ }^{\prime \prime}(\mathrm{NCN}) \mathrm{X}\right] / \mathrm{MMA}$ /(excess) $\mathrm{CCl}_{4}$ system solely affords the 1:1 Kharasch product is a direct consequence of the concentration of the reagents and the special ligand environment present, whereas systems like $\left[\mathrm{Ni}^{0}(\mathrm{CO})_{2}\left(\mathrm{PPh}_{3}\right)_{2}\right] / \mathrm{MMA} / \mathrm{CCl}_{4}{ }^{17 \mathrm{a}}$ and related $\mathrm{Ni}(\mathrm{II})$ systems $^{7 \mathrm{i}, \mathrm{I}}$ solely afford MMA polymerization. Another interesting aspect is that in our system we find saturation kinetics for the rate dependence on $\mathrm{CCl}_{4}$ concentration and a first-order dependence in alkene. In contrast, however, in the $\left[\mathrm{RuCl}_{2}\left(\mathrm{PPh}_{3}\right)_{3}\right]$ catalytic system studied by Matsumoto et al.8a-e and Davis et al., $8 \mathrm{~g}$ there is a first-order dependence in $\mathrm{CCl}_{4}$ and saturation ${ }^{8 g, 26}$ kinetic rate dependence of the alkene. This latter aspect leads them to introduce a reversible step involving alkene coordination. This ruthenium and the related $\mathrm{Pd}(\mathrm{OAc})_{2}-\mathrm{PPh}_{3}$ system ${ }^{4 l}$ are reported to be among the most active catalytic systems for the Kharasch addition reaction. Our catalytic system is at least as reactive as these systems, and our system effectively operates at ambient temperature under mild reaction conditions.

Two characteristic differences between our monoanionic ligand system and the commonly used neutral phosphine and amine ligands are (i) the well-defined organometallic coordination sphere is not easily disrupted owing to the combination of a $\mathrm{Ni}-\mathrm{C} \sigma$-bond with two chelate rings (the $\mathrm{M}-\mathrm{C}$ bond of the $\mathrm{Ni}$ catalyst is not involved at any stage in the reaction profile and appears to be 'protected' by the chelation of the $\mathrm{CH}_{2-}$ $\mathrm{NMe}_{2}$ ligand arms) and (ii) it is suitable for a number of modifications. We have, using this latter characteristic, not only successfully anchored catalytically active

(26) The authors ${ }^{8 g}$ prefer to use the term Michaelis-Menten to describe the rate dependence on alkene concentration.

\section{Scheme 3}


[Ni(NCN)X] sites to soluble polymers ${ }^{12 a}$ but have also prepared the first catalytically active carbosilane dendrimers. ${ }^{13}$ This is an important aspect in terms of applications of this technol ogy in a 'heterogeneous' (i.e., industrial) sense. Of further relevance is the unique opportunities that can be envisioned using this [ $\mathrm{Ni}$ $(\mathrm{NCN}) \mathrm{X}] / \mathrm{CCl}_{4}$ catalyst system. Sel ective system modification involving the temperature and reagent concentrations (Scheme 3) could be used to switch the catalytic behavior of the $\mathrm{Ni}$ complex in situ from polymerization to 1:1 Kharasch addition. This would lead to immediate termination of the living radical polymerization by a Kharasch 'capping' reaction (assuming kinetic control of the reaction according to $k_{\text {Kharasch }} \gg k_{\text {polymerization }}$ if $\left[\mathrm{CCl}_{4}\right] \gg$ [catalyst] at ambient temperature). A further beneficial result of this is that it would allow for facile recovery of the catalyst from the polymer matrix (since it is released from the polymer terminus) with concomitant introduction of useful hal ide substituents onto the end groups of the polymer chain (Scheme 3). We are currently exploring this possibility.

A final point worth emphasizing is that in the first step of the catalytic cycle, activation of $\mathrm{CCl}_{4}$, occurs in the absence of a free coordination site. ${ }^{27-30}$ This is a previously unrecognized concept in homogeneous catalysis that could be of fundamental significance in systems that comprise el ementary steps involving SET and metal species with an odd number of electrons.

\section{Experimental Section}

General. All reagents, except the arylnickel(II) complexes, were commercially available and used after appropriate purification. The alkenes were successively washed with $5 \%$ aqueous $\mathrm{NaOH}$ solution to remove inhibitors, washed twice with water, dried over $\mathrm{MgSO}_{4}$, filtered, and distilled under a nitrogen atmosphere. They were stored in the dark under a nitrogen atmosphere at $-30^{\circ} \mathrm{C}$. The polyhalogenated alkanes were dried over $\mathrm{MgSO}_{4}$, filtered, and distilled, except for carbon tetrabromide, which was recrystallized from ethanol. Solvents were dried and freshly distilled under a nitrogen atmosphere before use. The arylnickel(II) complexes were synthesized according to literature procedures. ${ }^{16}$ All manipulations of air-

(27) Preliminary molecular modeling studies (MM2 and ZINDO as implemented in CAChe Scientific software; Oxford Molecular Group) show that such an encounter species (A, Figure 6) is a viable intermediate, see: Grove, D. M. Unpublished results.

(28) For examples of isolated transition metal complexes that contain hal ogenated alkanes bound through halide-metal interactions, see: (a) Kulawiec, R. J .; Crabtree, R. H. Coord. Chem. Rev. 1990, 99, 89 and references given therein. (b) Peng, T.-S.; Winter, C. H.; Gladysz, J . A. Inorg. Chem. 1994, 33, 2534. (c) Pathak, D. D.; Adams, H.; White, C. J . Chem. Soc., Chem. Commun. 1994, 733.

(29) van der Zeijden, A. A. H.; van Koten, G.; Wouters, J. M. A.; Wijsmuller, W. F. A.; Grove, D. M. J . Am. Chem. Soc. 1988, 110, 5354

(30) van Beek, J. A. M.; van Koten, G.; Smeets, W. J .J .; Spek, A. L. J . Am. Chem. Soc. 1986, 108, 5010. 
sensitive nickel complexes and all catalytic experiments were carried out under a nitrogen atmosphere using Schlenk techniques.

GLC analyses were performed on a Varian 3400 gas chromatograph equipped with a FID and an internal integrator (column, CP Sil5 $(0.31 \mathrm{~mm} \times 30 \mathrm{~m}$ ); injector temperature, 250 ${ }^{\circ} \mathrm{C}$; detector temperature, $250^{\circ} \mathrm{C}$; temperature program, 105 ${ }^{\circ} \mathrm{C}, 3 \mathrm{~min}, 20^{\circ} \mathrm{C} \mathrm{min}^{-1}, 245^{\circ} \mathrm{C}, 5 \mathrm{~min}$ ) and on a Varian 3700 gas chromatograph equipped with a FID and a Shimadzu C-R3A Chromatopac integrator (col umn, 10\% Carbowax $20 \mathrm{M}$ on Chromosorb W, HP 80/100 mesh; injector temperature, 250 ${ }^{\circ} \mathrm{C}$; detector temperature, $250{ }^{\circ} \mathrm{C}$; temperature program, 65 ${ }^{\circ} \mathrm{C}, 2 \mathrm{~min}, 25^{\circ} \mathrm{C} \mathrm{min}-1,180^{\circ} \mathrm{C}, 3 \mathrm{~min}$ ). Reaction products were identified by GC-MS, NMR, and GLC and also by comparison with authentic samples.

ESR spectra were recorded in $\mathrm{CH}_{2} \mathrm{Cl}_{2}$ on a J EOL RE $2 \mathrm{X}$ ESR spectrometer at $-196{ }^{\circ} \mathrm{C}$ at the Department of Inorganic Chemistry, University of Leiden, under the supervision of Prof. Dr. J . Reedijk. UV-vis spectra were measured on Varian Cary 1 and Varian Cary 5 spectrophotometers. Infrared spectra were measured on a Perkin-EImer FT-IR 1800 (double beam) spectrometer. Gas-liquid chromatography-mass spectrometry was carried out using a J EOL J MS-AX505W spectrometer fitted with a Hewlett-Packard 5890 gas chromatograph (CP Sil5 column $(0.32 \mathrm{~mm} \times 25 \mathrm{~m}))$. Mass spectra, obtained under el ectron ionization conditions ( $70 \mathrm{eV}$ ), were recorded by linear scanning from $\mathrm{m} / \mathrm{z} 35-800$ at an accelerating voltage of $3 \mathrm{kV}$. Both FT-IR and GC-MS measurements were performed at the Department of Analytical Molecular Spectrometry, Utrecht University.

Standard Catalytic System. Prior to use, a mixture of methyl methacrylate $(3 \mathrm{~mL}, 28 \mathrm{mmol})$ and $\mathrm{CCl}_{4}(10 \mathrm{~mL}, 104$ $\mathrm{mmol}$ ) in $\mathrm{CH}_{2} \mathrm{Cl}_{2}(12 \mathrm{~mL}$ ) was degassed three times using the freeze-pump-thaw method. The catalyst $\left(9.1 \times 10^{-5} \mathrm{~mol}\right)$ was dissolved in $\mathrm{CH}_{2} \mathrm{Cl}_{2}(0.5 \mathrm{~mL})$ and subsequently added through a septum to the solution of alkene and $\mathrm{CCl}_{4}$ in $\mathrm{CH}_{2^{-}}$
$\mathrm{Cl}_{2}$. The reaction mixture was kept at $25.0 \pm 0.2^{\circ} \mathrm{C}$. The reaction was monitored by withdrawing samples at regular time intervals from the reaction mixture and analyzing them by GLC; dodecane was used as an internal standard.

Kinetic Studies. The kinetic experiments were performed in a manner similar to that described for the standard catalytic system. To determine the orders in the various reagents, the concentrations of the catalyst, $\mathrm{CCl}_{4}$, and alkene were varied during independent series of experiments. The total volume of the solution was maintained at $25.5 \mathrm{~mL}$ by adding sufficient $\mathrm{CH}_{2} \mathrm{Cl}_{2}$.

The activation parameters were determined by variation of the reaction temperature. The various temperatures were held constant by a constant temperature bath (Tamson NV, Holland, and Frigomix B. Braun, Melsungen).

Acknowledgment. We would like to thank Mr. M. Huisman, Mr. D. de Blauw, Mr. J .-P. van Rijswijk, and Mrs. P. M. F. C. Groot for their contributions to this research, Mr. F. Agterberg and Prof. Dr. J. Reedijk (University of Leiden) for some of the ESR measurements, Mr. C. van Sluis and Mrs A. van der Kerk for their assistance with the mass spectrometry studies, and Prof. Dr. R. Louw (University of Leiden) for his helpful comments concerning organic radical stabilities.

Supporting Information Available: Graphs of the firstorder dependence of the reaction rate $(\mathrm{k})$ vs catalyst ( $\mathrm{Ni}[\mathrm{NCN}$ $\mathrm{Br}$ ) concentration, $\mathrm{CH}_{3} \mathrm{CN}$ concentration, and MMA concentration, the log $\left(\mathrm{k} / \mathrm{k}_{\mathrm{o}}\right)$ vs Hammett substituent parameters $\left(\sigma_{\mathrm{p}}\right)$ for the addition of $\mathrm{CCl}_{4}$ to MMA by complexes 1-5, and correlation of the oxidation potential $E_{p, a}$ vs $\log \left(k / k_{0}\right)$ for complexes 1-5 (5 pages). Ordering information is given on any current masthead page.

OM970061E 